\title{
DEMOCRATIZAÇÃO DA ESCOLA PÚBLICA: IMPASSES E CONTROVÉRSIAS NA PRÁTICA PEDAGÓGICA ${ }^{1}$
}

Francisco Renato Lima (UFPI) ${ }^{2}$

\section{RESUMO}

O discurso sobre a democratização da escola pública constitui peça-chave em campanhas e projetos políticoeducacionais no Brasil, evidenciando necessidade de investimentos neste setor, no entanto, historicamente, também paralelo a esse discurso, vivencia-se uma prática marcada pelo negligenciamento e a falta de sistematização de políticas públicas que avancem nesse ideal. Diante desse problema, neste estudo discutese alguns impasses e controvérsias inerentes ao processo de democratização do ensino da escola pública, apontando para as possibilidades de superação destes dilemas, com vistas à otimização das práticas pedagógicas. Realizou-se uma pesquisa bibliográfica, de abordagem qualitativa, à luz das leituras de Behrens (2005), Dewey (1959), Freire (1998; 1997; 2000; 2003; 2006), Frigotto (2000), Mello (2003), Saviani (2003), entre outros. Percebe-se, ao lançar um rápido olhar sócio-histórico e ideológico sobre a questão, a inércia dos sistemas governamentais na estruturação dos sistemas de ensino público. Cada governo estabelece metas e planos, os quais incluem a educação, no entanto, há sempre camuflada, ou mesmo velada (como no atual governo), um descaso com o investimento em políticas públicas educacionais que cheguem ao chão da escola pública, fazendo dela um espaço democrático de construção e socialização de saberes.

Palavras-Chave: Escola Pública. Democratização. Políticas públicas educacionais. Prática Pedagógica.

\begin{abstract}
The discourse on the democratization of the public school can be used in political-educational campaigns and projects in Brazil, highlighting the need for investments in this sector, but historically, also parallel to this discourse, experiencing a practice marked by neglect and lack of systematization of public policies that advance this ideal. Given this problem, this study discusses some impasses and controversies inherent in the process of democratization of public school teaching, for the possibilities of overcoming these dilemmas, with a view to optimizing pedagogical practices. A qualitative bibliographic research was carried out in the light of the readings of Behrens (2005), Dewey (1959), Freire (1998; 1997; 2000; 2003; 2006), Frigotto (2000), Mello (2003), Saviani (2003), among others. For example, by taking a quick socio-historical and ideological look at an issue, an inertia of managed systems in structuring public education systems. Each government sets goals and plans, what are the rules for education, however, there is always camouflaged, or even veiled (as in the current government), a process of investment in educational public policies that reach the ground of the public school, making it a democratic space for building and socializing sabers.
\end{abstract}

Keywords: Public school. Democratization. Educational public policies. Pedagogical practice.

\footnotetext{
1 Trabalho apresentado no Congresso Brasileiro Ciência e Sociedade (CBCS 2019), promovido pelo Centro Universitário Santo Agostinho, de 03 a 05 de outubro de 2019, em Teresina-PI.

${ }^{2}$ Mestre em Letras - Estudos da Linguagem. Atualmente é Professor Substituto, Classe Auxiliar, Nível - I, da Universidade Federal do Piauí (UFPI). E-mail: fcorenatolima@hotmail.com 
ANAIS CBCS 2019 | 3 a 5 de outubro de 2019 | Centro Universitário Santo Agostinho - Teresina - PI

\section{CONSIDERAÇÕES INICIAIS}

Só existirá democracia no Brasil no dia em que se montar no país a máquina que prepara as democracias. Essa máquina é a da escola pública.

(Anísio Teixeira)

A referência de uma educação de qualidade constrói-se alicerçada por princípios de democracia, participação social e enfrentamento as divergências de ordem política e cultural. A democratização do ensino público alcança seu propósito na medida em que a escola seja um espaço de pluralidade de vozes, em que os sujeitos sejam partícipes de realidades compartilhadas, pela inserção social de tomada de decisões acerca de sua própria formação.

Pensar em uma escola pública democrática é primar pela construção de práticas pedagógicas articuladas entre o saber e o fazer dos agentes da educação. Os sujeitos da aprendizagem, professores e alunos, constroem-se pela relação dialógica e compactuada no espaço escolar. Para tanto, este deve reunir características de relativização de formas construção e de organização do saber institucionalizado.

Neste sentido, este estudo objetiva discutir alguns impasses e controvérsias inerentes ao processo de democratização do ensino da escola pública, apontando para as possibilidades de superação destes dilemas, com vistas à otimização das práticas pedagógicas. Do ponto de vista metodológico, constitui-se de um estudo qualitativo, realizado através de pesquisa bibliográfica, à luz das leituras de Behrens (2005), Dewey (1959), Freire (1998; 1997; 2000; 2003; 2006), Frigotto (2000), Mello (2003), Saviani (2003), entre outros que enriqueçam a discussão proposta.

As ideias apresentadas seguem a seguinte organização: apresentam-se os impasses, as controvérsias e os desafios para a democratização do ensino público; em seguida, discute-se o papel da escola pública e as concepções de um ensino democrático, conforme as teorias educacionais, apontando para a construção de práticas pedagógicas que envolvam a participação coletiva dos sujeitos da educação na organização do ensino público democrático; e conclui-se, ressaltando a necessidade de mudança de paradigmas na educação, a fim de potencializar a escola pública. 
ANAIS CBCS 2019 | 3 a 5 de outubro de 2019 | Centro Universitário Santo Agostinho - Teresina - P

\section{DEMOCRATIZAÇÃO DO ENSINO PÚBLICO: IMPASSES E CONTROVÉRSIAS}

A discussão acerca da democratização do ensino pública se envereda por diversos caminhos, que historicamente foram marcados por impasses e controvérsias que acentuam as distorções na efetivação de um ensino de qualidade, no alcance as demandas formativas, sociais, políticas e culturais exigidas da educação para o atendimento democrático a todos as camadas da esfera social, respeitando seus valores culturais e sociais.

A educação, enquanto prática social, e, no sentido pleno que a palavra remete significa, segundo a epistemologia do pedagogo alemão Schmied-Kowarzik (1983) apud Libâneo (2001, p. 07) pode ser definida a partir da seguinte consideração:

\footnotetext{
A educação é uma função parcial integrante da produção e reprodução da vida social, que é determinada por meio da tarefa natural e, ao mesmo tempo, cunhada socialmente da regeneração de sujeitos humanos, sem os quais não existiria nenhuma práxis social. A história do progresso social é simultaneamente também um desenvolvimento dos indivíduos em suas capacidades espirituais e corporais e em suas relações mútuas. A sociedade depende tanto da formação e da evolução dos indivíduos que a constituem, quanto estes não podem se desenvolver fora das relações sociais.
}

O autor refere-se a 'direitos humanos' e 'progresso social' como atividades conjuntas que se articulam na construção de uma sociedade democrática. Desse modo, a educação, deve partir dessa articulação, buscando elucidar pontos que promovam a formação crítica e o conhecimento plurilinear, que atenda aos anseios e as necessidades de todos. Porém, na prática, esse princípio 'emperra', considerando-se que os desníveis de condições de acesso e permanência a escola ainda constroem muros e distanciam os sujeitos da escola.

Embora, no Brasil, os discursos de 'uma educação para todos' circulem socialmente, a aplicação dessa teoria enfrenta muitas divergências. Existem realidades de ensino muito difíceis, tornando inoperante o propósito de uma educação que alcance as massas, com plenitude.

Dentre os muitos fatores, que interferem na efetiva democratização da escola pública, Mello (2003, p. 3-43) aponta para os dez maiores problemas da educação no Brasil e suas possíveis 
soluções, a partir do que já foi feito, o que está em curso o que falta fazer. O quadro, a seguir, apresenta as ideias da autora:

Quadro 01 - Os 10 maiores problemas da educação no Brasil (e suas possíveis soluções)

\begin{tabular}{|c|c|c|}
\hline & PROBLEMAS & POSSÍVEIS SOLUÇÕES \\
\hline \multirow[t]{3}{*}{1} & \multirow{3}{*}{$\begin{array}{l}\text { Cultura escolar elitista: herança } \\
\text { imperial: desde o seu surgimento, a } \\
\text { escola foi criada de 'cima para baixo', em } \\
\text { que os ricos estudam em escolas } \\
\text { particulares, com boas condições de } \\
\text { ensino; e os pobres estudam em escolas } \\
\text { públicas, que na grande maioria das } \\
\text { vezes, o sistema não garante condições } \\
\text { para o seu bom funcionamento e isso } \\
\text { acarreta um ensino de má qualidade. }\end{array}$} & $\begin{array}{l}\text { O que já foi feito } \\
\text { Acesso universal ao Ensino Fundamental e Ensino Médio e } \\
\text { Educação Infantil. }\end{array}$ \\
\hline & & $\begin{array}{l}\text { O que está em curso } \\
\text { Implementação da reforma curricular; trabalho junto à } \\
\text { imprensa; e discussão com as Universidades. }\end{array}$ \\
\hline & & $\begin{array}{l}\text { O que falta fazer } \\
\text { Consolidar a universalização do acesso; programas de } \\
\text { formação de diretores; e Debate mais amplo na sociedade. }\end{array}$ \\
\hline \multirow[t]{3}{*}{2} & \multirow[t]{3}{*}{$\begin{array}{l}\text { Visão estratégica: falta: o setor público } \\
\text { faz uma má gestão dos recursos } \\
\text { financeiros, e historicamente, o setor da } \\
\text { educação não fez parte da agenda } \\
\text { estratégica dos governos, dificultando } \\
\text { assim, a expansão e o desenvolvimento } \\
\text { de estratégias que busquem a } \\
\text { valorização da escola. }\end{array}$} & $\begin{array}{l}\text { O que já foi feito } \\
\text { O regime de colaboração está legalmente consolidado; a } \\
\text { educação foi colocada na agenda da reforma; O MEC criou um } \\
\text { padrão de atuação; plantou-se a semente de uma nova matriz } \\
\text { de política; Iniciativas de responsabilidade social de } \\
\text { empresas; cursos e concursos para pessoal de mídia; e } \\
\text { disponibilização de informações para a sociedade. }\end{array}$ \\
\hline & & $\begin{array}{l}\text { O que está em curso } \\
\text { Instâncias de acordo se reposicionando; reformulação das } \\
\text { visões e estratégias; grande efervescência de ideias e } \\
\text { propostas; ampliação do número de ONGs; jovens } \\
\text { profissionais de outras áreas; Mídia começa a aprender a } \\
\text { cobrir educação; e imprensa e sociedade estão começando a } \\
\text { aprender. }\end{array}$ \\
\hline & & $\begin{array}{l}\text { O que falta fazer } \\
\text { Dar curso político e institucional; fortalecer os canais de } \\
\text { participação da sociedade; superar a política educacional de } \\
\text { oferta descentralizada dos anos 90; aprofundar a educação } \\
\text { da mídia; e criar tradição de competência e respeito no uso } \\
\text { dos dados educacionais. }\end{array}$ \\
\hline 3 & $\begin{array}{l}\text { Gestão: sem eficiência e sem equidade: } \\
\text { há um desentendimento entre União, } \\
\text { Estados e Municípios, que tem } \\
\text { dificuldades de praticar o princípio } \\
\text { federativo e a divisão de tarefas para } \\
\text { formular e liderar as políticas de gestão } \\
\text { dos sistemas de ensino. }\end{array}$ & $\begin{array}{l}\text { O que já foi feito } \\
\text { O dinheiro do FUNDEF (instrumento de gestão) direto para o } \\
\text { aluno; o MEC assumiu de fato um papel estratégico: } \\
\text { coordenação nacional, avaliação e normatização; } \\
\text { fortaleceram-se as instâncias de negociação e coordenação } \\
\text { políticas; iniciou-se a profissionalização de quadros da } \\
\text { administração federal; e sistema de avaliação nacional do } \\
\text { rendimento escolar. }\end{array}$ \\
\hline
\end{tabular}


ANAIS CBCS 2019 | 3 a 5 de outubro de 2019 | Centro Universitário Santo Agostinho - Teresina - PI

\begin{tabular}{|c|c|c|}
\hline & & $\begin{array}{l}\text { O que está em curso } \\
\text { financiamento do FUNDEF; cursos de } \\
\text { stores educacionais; e cultura de avaliação }\end{array}$ \\
\hline & & $\begin{array}{l}\text { O que falta fazer } \\
\text { Ampliar e fortalecer as formas de controle no legislativo e nas } \\
\text { organizações sociais; fortalecer a cultura da avaliação; } \\
\text { fortalecer e valorizar a descentralização responsável da } \\
\text { gestão; enfrentar o corporativismo do setor público na } \\
\text { educação; valorizar a profissionalização dos quadros da } \\
\text { educação; e "Empowerment" de comunidades. }\end{array}$ \\
\hline \multirow[t]{3}{*}{4} & \multirow{3}{*}{$\begin{array}{l}\text { Desinformação da sociedade: há uma } \\
\text { distorção entre o que é a realidade da } \\
\text { docência mostrada pela mídia e a } \\
\text { realidade da escola. O professor não é } \\
\text { um coitadinho. }\end{array}$} & $\begin{array}{l}\text { O que já foi feito } \\
\text { Disponibilização de dados e informações relevantes e } \\
\text { confiáveis (site e publicações do MEC e de várias secretarias } \\
\text { estaduais). }\end{array}$ \\
\hline & & $\begin{array}{l}\text { O que está em curso } \\
\text { ONGs têm iniciativas para dar formação aos profissionais de } \\
\text { mídia; e campanhas de informação à opinião pública para } \\
\text { fortalecer o senso crítico na leitura da mídia. }\end{array}$ \\
\hline & & $\begin{array}{l}\text { O que falta fazer } \\
\text { Ampliar e consolidar trabalho junto aos distintos veículos e } \\
\text { profissionais de mídia; maior preparo dos gestores de política } \\
\text { pública para lidar com os meios de informação; e promover } \\
\text { debates e sensibilização para haver menos apego a factóides } \\
\text { e mais transparência na gestão educacional }\end{array}$ \\
\hline \multirow[t]{2}{*}{5} & \multirow[t]{2}{*}{$\begin{array}{l}\text { Interesses corporativos: uma série de } \\
\text { problemas, que inclui disputas entre } \\
\text { métodos de alfabetização; a formação } \\
\text { do professor tem que se sujeitar ao } \\
\text { ensino superior disciplinarista; alto } \\
\text { índice de repetência; fragmentação } \\
\text { curricular; entre outros problemas de } \\
\text { diferentes interesses. }\end{array}$} & $\begin{array}{l}\text { O que já foi feito } \\
\text { Criação do FUNDEF; reorganização de todas as estatísticas; } \\
\text { diretrizes nacionais para carreira e revisão do sistema de } \\
\text { formação de professores; criação do ISE - Instituto Superior } \\
\text { de Educação; avaliação de resultados e incentivos em alguns } \\
\text { estados ou municípios; e preservação do recurso vinculado } \\
\text { para salários dos ativos. }\end{array}$ \\
\hline & & $\begin{array}{l}\text { O que está em curso } \\
\text { Reforma da Previdência para separar salários de ativos e } \\
\text { inativos; enfrentar as Instituições de Ensino Superior e } \\
\text { implementar o novo sistema de formação de professores; } \\
\text { estudos de novas estruturas de carreira; e estudos de } \\
\text { alternativas como as Charter Schools americanas. }\end{array}$ \\
\hline
\end{tabular}


ANAIS CBCS 2019 | 3 a 5 de outubro de 2019 | Centro Universitário Santo Agostinho - Teresina - P

\begin{tabular}{|c|c|c|}
\hline & & $\begin{array}{l}\text { O que falta fazer } \\
\text { Mudanças na carreira; esclarecer a sociedade sobre carreira } \\
\text { e salário de professores; incentivar criação de ISEs nas } \\
\text { universidades; fortalecer e disseminar cultura de avaliação de } \\
\text { resultados e incentivos; e "Empowerment" das comunidades } \\
\text { e famílias. }\end{array}$ \\
\hline \multirow[t]{3}{*}{6} & \multirow{3}{*}{$\begin{array}{l}\text { Perigo das "causas nobres": algumas } \\
\text { delas, por exemplo, o ensino } \\
\text { fundamental de nove anos para colocar } \\
\text { todas as crianças de seis anos na escola, } \\
\text { dividindo assim, os recursos com mais } \\
\text { alunos; tempo integral para as crianças } \\
\text { na escola, para que ela tenha um } \\
\text { atendimento integral, sendo que dobrar } \\
\text { turno pode não ser produtivo; e a } \\
\text { proliferação da ideia "Educação se faz } \\
\text { com afeto" - um tanto quanto ilusória. }\end{array}$} & $\begin{array}{l}\text { O que já foi feito } \\
\text { Sistema de informações confiáveis é a base para desmistificar } \\
\text { essas ideias. }\end{array}$ \\
\hline & & $\begin{array}{l}\text { O que está em curso } \\
\text { Debate permanente no setor; e linguagem nova por parte de } \\
\text { alguns veículos. }\end{array}$ \\
\hline & & $\begin{array}{l}\text { O que falta fazer } \\
\text { Informar cada vez melhor a opinião pública; mostrar a } \\
\text { verdade por trás das informações distorcidas ou incompletas; } \\
\text { e sensibilizar os "papas" da mídia para o problema da } \\
\text { informação sobre educação e da vulnerabilidade da área para } \\
\text { o estelionato ideológico. }\end{array}$ \\
\hline \multirow[t]{3}{*}{7} & \multirow[t]{3}{*}{$\begin{array}{l}\text { Fracasso escolar: reprovação, } \\
\text { repetência, evasão: até os anos 90, } \\
\text { estava entre os piores indicadores de } \\
\text { qualidade do mundo. }\end{array}$} & $\begin{array}{l}\text { O que já foi feito } \\
\text { A LDB abriu todas as possibilidades no plano normativo; } \\
\text { subsídios de diferentes tipos elaborados pelo MEC, CNE e } \\
\text { sistemas; revisto o sistema de formação inicial de professores } \\
\text { em nível superior; e ineficiência e ineficácia da repetência } \\
\text { comprovadas pelo SAEB e sistemas estaduais de avaliação. }\end{array}$ \\
\hline & & $\begin{array}{l}\text { O que está em curso } \\
\text { Ações para prevenir o fracasso: ciclagem do período escolar, } \\
\text { revisão dos critérios de avaliação, programas de capacitação } \\
\text { em serviço dos professores; incentivos para escolas que } \\
\text { desenvolvem projetos bem sucedidos de diminuição da } \\
\text { repetência e evasão; regularização do fluxo escolar; e } \\
\text { implementação de cursos de formação inicial em nível } \\
\text { superior. }\end{array}$ \\
\hline & & $\begin{array}{l}\text { O que falta fazer } \\
\text { Inventariar e documentar tudo o que está sendo feito; avaliar, } \\
\text { ampliar, consolidar e promover melhorias no que foi iniciado; } \\
\text { continuar sensibilizando os professores para a necessidade e } \\
\text { mudar a cultura; e informar a opinião pública sobre os } \\
\text { malefícios da repetência e da cultura elitista e sobre o que } \\
\text { está sendo feito. }\end{array}$ \\
\hline 8 & $\begin{array}{l}\text { Qualidade: ainda em discussão: } \\
\text { perpassa por alguns fatores, como por } \\
\text { exemplo: garantia do acesso à educação } \\
\text { para todos; padrões de mínimos de }\end{array}$ & $\begin{array}{l}\text { O que já foi feito } \\
\text { Novas Diretrizes e Parâmetros Curriculares; avaliação do livro } \\
\text { didático; novos materiais para professores e alunos; e cursos } \\
\text { e materiais para gestores. }\end{array}$ \\
\hline
\end{tabular}


ANAIS CBCS 2019 | 3 a 5 de outubro de 2019 | Centro Universitário Santo Agostinho - Teresina - PI

\begin{tabular}{|c|c|c|}
\hline & \multirow{2}{*}{$\begin{array}{l}\text { qualidade; atendimento as necessidades } \\
\text { de uma população heterogênea; } \\
\text { reconhecimento e valorização da figura } \\
\text { do professor. }\end{array}$} & $\begin{array}{l}\text { O que está em curso } \\
\text { Implementação do que já foi feito; educação continuada para } \\
\text { professores e investimento na gestão. }\end{array}$ \\
\hline & & $\begin{array}{l}\text { O que falta fazer } \\
\text { Consolidar e ampliar as medidas de melhoria, na formação do } \\
\text { professor e na produção, ampliação e diversificação de } \\
\text { recursos de apoio didático para a sala de aula; e produzir e } \\
\text { implementar modelos de gestão escolar para aprendizagens } \\
\text { relevantes. }\end{array}$ \\
\hline \multirow[t]{3}{*}{9} & \multirow{3}{*}{$\begin{array}{l}\text { Despreparo dos professores: ao longo } \\
\text { da história os modelos de formação do } \\
\text { professor foram distorcidos, desde os } \\
\text { problemas nas escolas universitárias de } \\
\text { formação do professor, o que implica na } \\
\text { qualidade de sua prática; os professores } \\
\text { não sabem ensinar crianças diferentes } \\
\text { do aluno ideal criado pela cultura da } \\
\text { academia; os vícios do setor público, } \\
\text { como o formalismo e cartorialismo, falta } \\
\text { de planos de formação, salários e } \\
\text { carreira, entre outros problemas que } \\
\text { fragmentam as estruturas curriculares e } \\
\text { a prática do professor em sala de aula. }\end{array}$} & $\begin{array}{l}\text { O que já foi feito } \\
\text { Novas normas para os cursos de formação; e diretrizes para } \\
\text { carreira de professores como condição para receber recursos } \\
\text { do FUNDEF. }\end{array}$ \\
\hline & & $\begin{array}{l}\text { O que está em curso } \\
\text { Criação dos ISEs (Institutos Superiores de Educação); novo } \\
\text { currículo de formação de professores; programas de } \\
\text { educação continuada; cursos de certificação para professores } \\
\text { que não têm o nível superior; e metodologia e materiais para } \\
\text { vários cursos, em larga escala. }\end{array}$ \\
\hline & & $\begin{array}{l}\text { O que falta fazer } \\
\text { ISO } 9000 \text { da Formação de Professores visando a melhoria de } \\
\text { qualidade dos cursos de formação existentes; avaliação e } \\
\text { certificação dos professores em exercício; e aumentar e } \\
\text { diversificar a produção de material para os cursos de } \\
\text { formação inicial e continuada de professores. }\end{array}$ \\
\hline \multirow[t]{3}{*}{10} & \multirow[t]{3}{*}{$\begin{array}{l}\text { Desafagem: longe do século XXI: é } \\
\text { preciso superar a herança imperial } \\
\text { (escola para poucos; acadêmica, } \\
\text { enciclopédica e distante da vida), para } \\
\text { ter uma educação democrática; e } \\
\text { sintonizar a educação com as demandas } \\
\text { da sociedade do conhecimento do final } \\
\text { do século XX e início do XXI. }\end{array}$} & $\begin{array}{l}\text { O que já foi feito } \\
\text { Visão estratégica e gestão sintonizadas com as demandas do } \\
\text { novo século; a reforma curricular já está sintonizada com as } \\
\text { novas demandas e vai na mesma direção das de outros } \\
\text { países: Inglaterra, EUA, Espanha, Portugal; e o Fundo de } \\
\text { Universalização dos Serviços de Telecomunicações (FUST) } \\
\text { reservou recursos para introduzir as novas Tecnologias da } \\
\text { Comunicação e Informação (TCl) - nas escolas. }\end{array}$ \\
\hline & & $\begin{array}{l}\text { O que está em curso } \\
\text { Implementação pelo governo e pela sociedade; debate sobre } \\
\text { o "para que" educamos; e inclusão digital do professor. }\end{array}$ \\
\hline & & $\begin{array}{l}\text { O que falta fazer } \\
\text { Consolidar, avaliar, ajustar, aperfeiçoar os projetos já em } \\
\text { andamento; arejar os canais de participação para que a } \\
\text { sociedade expresse suas expectativas quanto ao que deve ser } \\
\text { a educação para o mundo digital; viabilizar o uso dos recursos } \\
\text { do FUST; e inclusão digital do professor deve ter prioridade. }\end{array}$ \\
\hline
\end{tabular}

Fonte: MELLO (2003) 
ANAIS CBCS 2019 | 3 a 5 de outubro de 2019 | Centro Universitário Santo Agostinho - Teresina - PI

Ainda que os dados apontados pela autora sejam do ano 2003, é possível a partir deles, traçar um perfil da realidade da educação brasileira. Muitos desses desafios e metas já foram superados; outros não; a realidade impõe novos. O atual contexto, embora vivencie-se as transitoriedades e os desafios de uma sociedade pós-moderna, no final da segunda década do século XXI, ainda é cerceado de mecanismos e formas de poder institucionalizado, que bloqueiam a legitimação plena dos direitos cidadãos básicos que perpassam pela escola.

Quanto ao desafio de universalização do ensino básico, o que pressupõe condições mínimas de acesso ao Ensino Fundamental, Silva (2009, p. 19) aponta que "o País vivencia, desde o final do século XX, um período de melhoria significativa em todos os indicadores que medem as oportunidades de acesso, permanência, aprendizagem e conclusão da educação básica". Nesse cenário, a autora chama atenção para o fato de que: "nosso desafio, em pleno século XXI, é estruturar uma escola republicana, que seja realmente para todos. O que muitos países fizeram no século XIX, outros no século XX, e o Brasil está fazendo agora! Mas em educação, urgência não é sinônimo de pressa" (p. 24). E, portanto, "não é apenas incluir os meninos e meninas na escola, mas encontrar novas linguagens, novas categorias, novas palavras para enfrentar formas inéditas de exclusão que, hoje, se produzem e reproduzem" (SILVA, 2009, p. 22).

Ou seja, uma escola que se proponha a ser um espaço democrático, para a construção da cidadania, mais do ensinar conteúdos, se preocupa com a construção de saberes, por meio do investimento contínuo e processual em políticas públicas de formação de professores e de fortalecimento das ações de combate ao analfabetismo e a evasão escolar, por exemplo. Saviani (2003, p. 117) considera que:

[...] é necessário um grau de mobilização e de organização que pressione o estado e o conjunto da sociedade, no intuito que a educação venha a assumir o caráter de prioridade efetiva e com isto os recursos necessários venham a ser destinados. De outro lado, essa situação precária coloca o desafio de mobilização e de organização do próprio trabalho docente, de modo que no interior da própria ação pedagógica se desenvolvam os mecanismos que se contraponham a esse estado de coisas. 
ANAIS CBCS 2019 | 3 a 5 de outubro de 2019 | Centro Universitário Santo Agostinho - Teresina - P

A 'organização do trabalho docente', referida pelo autor, pressupõe o investimento antes mencionado. Os setores da sociedade (públicos, privados, corporativos etc.) precisam alinhar vozes no sentido de considerar a escola pública como prioridade nas ações governamentais, executado ações e políticas públicas que valorizem o potencial da escola pública, afinal, o seu histórico papel na sociedade é o de oportunizar espaços de acesso ao poder saber e garantir a dignidade social.

\section{ESCOLA PÚBLICA: AS PRÁTICAS PEDAGÓGICAS E AS CONCEPÇÕES DE ENSINO DEMOCRÁTICO NA PERSPECTIVA DE UM IDEAL DE ENSINO}

O lugar da escola pública como espaço de construção e democratização do saber configurase como um marco histórico nas lutas e movimentos sociais por uma educação de qualidade. Nesta trajetória, muitos envolveram diretamente com os movimentos das classes, dentre eles: Anísio Teixeira, Fernando Azevedo, Lourenço Filho, Afrânio Peixoto, entre outros intelectuais responsáveis pela difusão das ideias do Movimento da Escola Nova no Brasil, na cidade do Rio de Janeiro, entre os anos de 1930 e 1935, marcado pelo lançamento do Manifesto dos Pioneiros da Educação Nova, em 1932, que se constitui como "um marco desse movimento: ao mesmo tempo em que questionava os métodos tradicionais de ensino, buscava afirmar, em uma sociedade como a obrigatoriedade, a gratuidade, a laicidade e a com educação" (LOPES; GALVÃO, 2001, p. 23).

O desenvolvimento dessa proposta empreendeu a proposição de reformas importantes para o ensino público brasileiro, porém, entre o teórico e o prático ainda existem muitas lacunas. 0 ensino público brasileiro carrega as marcas das desigualdades culturais, econômicas e políticas, que afetam diretamente aqueles que são principais beneficiários e requerentes deste direito: o aluno.

A escola é o espaço da construção e da mudança na sociedade, de forma a formar os indivíduos para o engajamento crítico e participativo nas lutas pela manutenção dos direitos adquiridos por lei, favorecendo o exercício da cidadania; porém, na prática, muito há de se avançar nesta demanda. De acordo com Gryzybowski (1968) apud Frigotto (2000, p. 26): 


\section{CONQEEESSOCIENCIAESOCIEDADE

ANAIS CBCS 2019 | 3 a 5 de outubro de 2019 | Centro Universitário Santo Agostinho - Teresina - PI

[...] a educação é, antes de mais nada, desenvolvimento de potencialidades e a apropriação de 'saber social' (conjunto de conhecimentos e habilidades, atitudes e valores que são produzidos pelas classes, em uma situação histórica dada de relações para dar conta de seus interesses e necessidades). Trata-se de buscar, na educação, conhecimentos e habilidades que permitam uma melhor compreensão da realidade e envolva a capacidade de fazer valer os próprios interesses econômicos, políticos e culturais.

É neste sentido que se discute a urgência por uma escola de qualidade que atenda aos anseios de uma educação democrática e participativa, tendo em vista que, muitos ainda são excluídos e marginalizados desse processo. É preciso a adoção de uma ideia de ensino pautado na consciência, no compromisso contra as hegemonias dominantes e as políticas de exclusão social e homogeneização do ensino público.

A escola como espaço de socialização do conhecimento deve estar aberta para a construção e reconstrução do conhecimento, por meio de uma relação democrática, que se configure pela forma como as oportunidades de relativizar o ensino, tendo em vista que "uma democracia é mais do que uma forma de governo; é, principalmente, uma forma de vida associada, de experiência conjunta e mutuamente comunicada" (DEWEY, 1959, p. 93).

Pensar em um ensino democrático pressupõe considerar a escola como espaço de convivências múltiplas, onde a valorização da diferença seja princípio articulador de aprendizagem entre os sujeitos. As práticas pedagógicas devem desafiar os alunos a buscarem a autonomia e a reconfiguração da sociedade excludente e celetista que ora se apresenta.

As práticas pedagógicas devem estar fundamentadas em concepções de ensino que tenham a ideia da autonomia implícita em sua constituição teórica, entendendo-a como "a possibilidade e a capacidade de a escola elaborar e implementar um projeto político-pedagógico que seja relevante à comunidade e à sociedade a que serve" (NEVES, 1995, p. 113), corroborando assim, a construção de um novo modelo social de ensino e de sociedade.

Sobre os processos de ensino e aprendizagem de forma democrática, Freire (1998, p. 28) chama a atenção para o papel do educador, alegando que ele "não pode negar-se o dever de, na sua prática docente, reforçar a capacidade crítica do educando, sua curiosidade, sua insubmissão", 
ANAIS CBCS 2019 | 3 a 5 de outubro de 2019 | Centro Universitário Santo Agostinho - Teresina - PI

mas deve promover a discussão rigorosa que aproxime o aluno e o objeto de conhecimento de forma a transformar a realidade, pois

Toda prática educativa demanda a existência de sujeito, um que ensinando, aprende, outro que, aprendendo, ensina, daí o seu cunho gnosiológico; a existência de objetos, conteúdos a serem ensinados e aprendidos; envolve o uso de métodos, de técnicas, de materiais; implica função de seu caráter diretivo, objetivo, sonhos, utopias ideais. Daí a sua politicidade, qualidade que tem a prática educativa de ser política, de não poder ser neutra (FREIRE, 1998, p. 77).

A escola precisa então, redimensionar o seu papel, reformulando suas práticas, no sentido de oportunizar que a aprendizagem seja manifesta por meio de relações articuladas entre quem ensina e quem aprende, superando a noção diretiva e verticalizada da relação ensino e aprendizagem - professor só ensina, aluno apenas aprende -, e adotar uma atitude dialética e consciente. Essa conscientização, segundo Freire (2006, p. 30), "implica, pois, que ultrapassemos a esfera espontânea de apreensão da realidade, para chegarmos a uma esfera crítica na qual a realidade se dá como objeto cognoscível e na qual o homem assume uma posição epistemológica".

Nessa relação de reconhecimento de papeis e respeito ao espaço de construção da cidadania do outro, que é a sala de aula, Freire (2003) ainda coloca:

Para mim é impossível compreender o ensino sem o aprendizado e ambos sem o conhecimento. No processo de ensinar há o ato de saber por parte do professor. 0 professor tem que conhecer o conteúdo daquilo que ensina. Então para que ele ou ela possa ensinar, ele ou ela tem primeiro que saber e, simultaneamente com o processo de ensinar, continuar a saber por que o aluno, ao ser convidado a aprender aquilo que o professor ensina, realmente aprende quando é capaz de saber o conteúdo daquilo que lhe foi ensinado. (p. 79)

O educando precisa assumir-se como tal, mas assumir-se como educando significa reconhecer-se como sujeito que é capaz de conhecer o que quer conhecer em relação com o outro sujeito igualmente capaz de conhecer, o educador e, entre os dois, possibilitando a tarefa de ambos, o objeto de conhecimento. Ensinar e aprender são assim momentos de um processo maior - o de conhecer, que implicar re-conhecer. (p. 47)

Essa posição de assunção epistemológica do homem, apontada por Freire (2003) pressupõe, que lhe sejam oportunizadas, nas relações sociais que estabelece com os pares e com as instituições as quais se vincula (principalmente a escola), a oportunidade de pensar e agir criticamente sobre o 
ANAIS CBCS 2019 | 3 a 5 de outubro de 2019 | Centro Universitário Santo Agostinho - Teresina - P

objeto cognoscível, de modo a transformá-lo no processo de aprendizagem, transformando a si mesmo e o mundo, pois "a práxis, porém, é reflexão e ação dos homens sobre o mundo para transformá-lo. Sem ela, é impossível a superação da contradição opressor-oprimido", afirma Freire (1997, p. 38), ao apontar para uma educação crítica como tomada de consciência do mundo.

\section{CONSIDERAÇÕES FINAIS}

A organização do ensino na escola pública, sob uma perspectiva democrática parte do princípio de ruptura e descontinuidade com velhos paradigmas de construção do conhecimento. Viabiliza-se pela necessidade de renovação das práticas de ensino e aprendizagem nas escolas, buscando superar os paradigmas conservadores de mera reprodução do conhecimento, que limitam a criatividade e dos alunos. Este modelo de ensino é decorrente da influência do paradigma newtoniano-cartesiano na educação, que se instaurou através das abordagens tradicional e tecnicista de ensino (BEHRENS, 2005).

Este dilema apresenta-se como elemento de burocratização do ensino público. Há, portanto, a necessidade de renovação das práticas pedagógicas, inovando no pensar e no fazer de sala de aula, fazendo desta um espaço harmonioso de aprendizagem, em que os sujeitos construam-se de forma interdependentes e capazes de ressignificar suas ações e papeis sociais. É neste sentido que surgem novas concepções pedagógicas que possam contribuir para a consolidação de um ensino articulado entre saber acadêmico institucionalizado e saber de mundo, integrando-se ambos, para a efetivação de um ensino democrático.

Nesse sentido, a coexistência de sujeitos que, marcados pela heterogeneidade, consigam atuar como autênticos agentes da dialogicidade e da aprendizagem mútua. $\mathrm{O}$ espaço da sala de aula da escola pública deve constituir-se como campo de alinhamento de forças e vozes sociais, da gestão e do conhecimento colaborativo, através de práticas que tenham sentido e intencionalidade para professores e alunos, como agentes de transformação e mudança social de seu tempo. 


\section{CONQEEESSO CIENCIASSOCIEDADE \\ Inovação, Diversidadie e Sustentahilitidadie}

ANAIS CBCS 2019 | 3 a 5 de outubro de 2019 | Centro Universitário Santo Agostinho - Teresina - PI

\section{REFERÊNCIAS}

BEHRENS, Marilda A. O paradigma emergente e a prática pedagógica. Petrópolis: Vozes, 2005.

DEWEY, J. Democracia e educação: introdução à Filosofia da Educação. 3. ed. Trad. Godofredo Rangel e Anísio Teixeira. São Paulo: Companhia Editora Nacional, 1959.

FREIRE, Paulo. Pedagogia da autonomia: saberes necessários à prática educativa. São Paulo: Paz e Terra, 1998.

FREIRE, Paulo. Pedagogia da esperança. 13. ed. Rio de Janeiro: Paz e Terra, 2006.

FREIRE, Paulo. Pedagogia do oprimido. 24. ed. Rio de Janeiro: Paz e Terra, 1997.

FREIRE, Paulo. Cartas a Cristina: reflexões sobre minha vida e minha práxis. 2. ed. São Paulo: UNESP, 2003.

FRIGOTTO, Gaudêncio. Educação e crise do capitalismo real. São Paulo: Cortez, 2000.

LIBÂNEO, José Carlos. Pedagogia e pedagogos: inquietações e buscas. Educar, Curitiba, n. 17, p. 153-176. 2001. Editora da UFPR.

LOPES, E. M. I; GALVÃO, A. M. O. História da educação. Rio de Janeiro: DP\&A, 2001.

MELLO, Guiomar Namo de. Os 10 maiores problemas da Educação Básica no Brasil (e suas possíveis soluções). Revista Escola. Edição Fatima Ali, 2003. Disponível em: < http://revistaescola.abril.com.br/img/politicas-publicas/fala_exclusivo.pdf $>$. Acesso em: 10 set. 2019.

NEVES, Carmem M. de Castro. Autonomia da escola pública: um enfoque operacional. In: VEIGA, Ilma Passos A. (Org.). Projeto político-pedagógico da escola: uma construção possível. 7. ed. Campinas: Papirus, 1995. p. 95-129.

SAVIANI, Demerval. Pedagogia histórico-crítica: primeiras aproximações. 8. ed. Campinas: Autores Associados, 2003.

SILVA, Maria do Pilar Lacerda Almeida e. A Educação Básica: avanços e desafios. Secretaria de Educação Básica. Ministério da Educação, 2009. Disponível em: < file:///C:/Users/RV415\%20STARTER/Downloads/educacao basica_brasil_avancos desafios.pdf $>$. Acesso em: 10 set. 2019. 